ORIGINAL ARTICLE

\title{
Prevelance of Undiagnosed Bronchiectasis in Patients Suffering from Severe Persistent Asthma
}

\author{
ASAD JAVAID ${ }^{1}$, MUHAMMAD SAQIB MUSHARAF², FAISAL HASSAN ZAHID CHAUDERY ${ }^{3}$, MUHAMMAD TAHA WAQAS ${ }^{4}$, \\ MUHAMMAD MOHSIN FAROOQ ${ }^{5}$, RASHID ALI ${ }^{6}$ \\ ${ }^{1,3}$ Senior Registrars, ${ }^{2}$ Assitant Professor, Department of Pulmonology, Al-Aleem Medical College/Gulab Devi Teaching Hospital Lahore \\ ${ }^{4}$ Senior Registrar, Department of Pulmonology, Shalamar Hospital Lahore \\ ${ }^{5}$ Senior Registrar, Department of Pulmonology, Sheikh Zayed Rahim Yar Khan \\ ${ }^{6}$ Senior Registrar, Department of Pulmonology, Akhtar Saeed Medical \& Dental college, Lahore \\ Correspondence to: Dr. Asad Javaid, E-mail: drasadjavaid@gmail.com Cell: 0300-8404381
}

\begin{abstract}
Introduction: Asthma is a clinical condition associated with recurring airway obstruction, airway hyperresponsiveness and airway inflammation. Asthma and bronchiectasis are separate illnesses. However, both disorders occur in some patients e.g., ABPA. Rare data exist for determining the impact of asthma aggravation by bronchiectasis. Present study aims to find such association.

Objective: To determine the prevalence of undiagnosed bronchiectasis in patients suffering from severe persistent asthma.

Study Design: Cross sectional/descriptive study

Place and Duration of Study: Department of Pulmonology, Al-Aleem Medical College/Gulab Devi Teaching Hospital Lahore from $1^{\text {st }}$ July 2020 to $31^{\text {st }}$ December 2020.

Methodology: One hundred and twenty five patients of severe persistent asthma were enrolled. Patients were aged between 20-75 years. Patients details demographics age, sex and body mass index were recorded after taking written consent. High-resolution computed tomography (HRCT) chest was done among complete patients to recognized undiagnosed bronchiectasis. Prevalence of undiagnosed bronchiectasis was assessed among cases.

Results: Sixty five (54.17\%) were females and the rest were males 55 (45.83\%). Mean age of the patients were $40.26 \pm 9.55$ years with mean BMI $25.16 \pm 8.66 \mathrm{~kg} / \mathrm{m}^{2} .35(28 \%)$ patients had smoking history. Majority of the patients 55 (44\%) were aged between 45-75 years of age. Prevalence of undiagnosed bronchiectasis was found in $48(38.4 \%)$ patients of severe persistent asthma.

Conclusion: The prevalence of undiagnosed bronchiectasis was significantly high among patients of long disease duration suffering from persistent asthma.

Keywords: Severe persistent, Asthma, Undiagnosed bronchiectasis
\end{abstract}

\section{INTRODUCTION}

Asthma is a clinical condition associated with recurring airway obstruction, airway hyperresponsiveness and airway inflammation. Asthma is thus a syndrome. Exacerbation of asthma is demonstrated through periods of increasing shortness of breath, coughing, tightening of chest or a combination of such symptoms. Asthma exacerbations involve a range of risk factors, such allergens, viral infections, pollution, medicines, obesity, emotional stress, rhinitis, sinusitis, and GERD. ${ }^{1}$

Bronchiectasis is characterized by persistently dilating airways because of the inadequate clearance of different microorganisms and of recurrent or chronic infections of the bronchial inflammatory system. ${ }^{2}$

While in most places, the real prevalence is not known, bronchiectasis in North America and around the globe is currently being diagnosed more frequently. ${ }^{3}$ The bronchiectasis diagnosis is based on the examination of clinical history and characteristic patterns on HRCT.

Asthma and bronchiectasis are separate illnesses. However, both disorders occur in some patients e.g. ABPA. Rare data exist for determining the impact of asthma aggravation by bronchiectasis. We have only one report to our knowledge about the impact of asthma coexisting

Received on 13-02-2021

Accepted on 09-06-2021 bronchiectasis. ${ }^{4}$ Many clinical asthma studies nonetheless omit patients with bronchiectasis. The disorders include airflow obstruction and respiratory symptoms, which imitate asthma. COPD and bronchial fibrosis, constrictive bronchiolitis and congestive cardiac failure are among them. Scanning with HRCT is important for the diagnostics of serious asthma patients.

In asthmatic patients, the rate of bronchiectasis ranges from $9 \%$ to $77 \%$ with a median of $31 \%$. $^{5-7}$ The large range in the incidence of bronchiectasis observed is largely related to patient population variances and scanning procedures. In a research by Gupta et al ${ }^{8}$ studying HRCT chest scanning in individuals with severe asthma, 40 percent of these patients had bronchiectasis. In another study, 26 patients with asthma reported prevalence of bronchiectasis $(24.8 \%){ }^{9}$

\section{MATERIAL AND METHODS}

This descriptive/cross-sectional study was conducted at Department of Pulmonology, Al-Aleem Medical College/Gulab Devi Teaching Hospital Lahore from $1^{\text {st }}$ July 2020 to $31^{\text {st }}$ December 2020 and consisted of 125 patients of severe persistent asthma. Patient's details demographics were recorded after taking informed written consent. Patients who had cardiac disease, liver cirrhosis and those did not give any written consent were excluded from this study. Patients were aged between $20-75$ years. 
Patients details demographics age, sex and body mass index were recorded after taking written consent. Highresolution computed tomography chest was done to diagnose bronchiectasis. Prevalence of undiagnosed bronchiectasis was then assessed among cases. Complete data was analyzed by SPSS 22 .

\section{RESULTS}

There were $65(54.17 \%)$ females, and the rest were males $55(45.83 \%)$. Mean age of the patients were $40.26 \pm 9.55$ years with mean BMl $25.16 \pm 8.66 \mathrm{~kg} / \mathrm{m}^{2}$. Thirty-five (28\%) patients had smoking history. Majority of the patients 55 (44\%) were aged between $45-75$ years of age (Table 1 ). Prevalence of undiagnosed bronchiectasis was found in 48 (38.4\%) among patients of severe persistent asthma (Table 2). Among 48 cases of undiagnosed bronchiectasis, majority of the patients $28(58.33 \%)$ were males as compared to females 20 (41.67\%) [Table 3].

Table 1: Baseline details demographics of enrolled cases

\begin{tabular}{|l|l|l|}
\hline Variables & No. & $\%$ \\
\hline Mean age (years) & $40.26 \pm 9.55$ & \multicolumn{2}{|l|}{} \\
\hline Mean BMl (Kg/m $\left.{ }^{2}\right)$ & $25.16 \pm 8.66$ \\
\hline Gender & 55 & 45.83 \\
\hline Male & 65 & 54.17 \\
\hline Female & 35 & 28.0 \\
\hline Smoking History & 90 & 72.0 \\
\hline Yes & \multicolumn{2}{|l|}{} \\
\hline No & 33 & 26.4 \\
\hline Age difference (years) & 37 & 29.6 \\
\hline $20-35$ & 55 & 44.0 \\
\hline $35-45$ &
\end{tabular}

Table 2: Frequency of undiagnosed bronchiectasis among cases $(\mathrm{n}=125)$

\begin{tabular}{|l|l|l|}
\hline Undiagnosed bronchiectasis & No. & $\%$ \\
\hline Yes & 48 & 38.4 \\
\hline No & 77 & 61.6 \\
\hline
\end{tabular}

Table 3: Association of undiagnosed bronchiectasis with respect to gender $(n=48)$

\begin{tabular}{|l|l|l|}
\hline Gender & No. & $\%$ \\
\hline Male & 28 & 58.33 \\
\hline Female & 20 & 41.67 \\
\hline
\end{tabular}

\section{DISCUSSION}

In individuals with severe asthma, bronchiectasis is usually missed even when typical symptoms are presented that are suitable for diagnosis. Thus, related disorders as the cause of respiratory symptoms and uncontrolled asthma need to be examined in individuals with severe asthma. Highresolution computed tomography scanning is part of asthma management, though it differs between centers. In diagnosis and treatment plan of severe asthma patients, HRCT scanning plays a major role to rule out associated diseases.

Majority of the patients were females $54.17 \%$. Mean age of the patients were $40.26 \pm 9.55$ years with mean BMl $25.16 \pm 8.66 \mathrm{~kg} / \mathrm{m}^{2} .35(28 \%)$ patients had smoking history among 125 cases. Majority of the patients 55 (40\%) were aged between $45-75$ years of age. Our findings are comparable to the previous some studies. $8,10,11$ Among 48 cases of undiagnosed bronchiectasis, majority of the patients $28(58.33 \%)$ were males as compared to females $20(41.67 \%)$. According to literature, bronchial prevalence ranges between $2.2 \%{ }^{12}$ and $77 \%{ }^{13}$ among people with asthma. Neeld et $\mathrm{al}^{14}$ has shown a high incidence of asthma bronchiectasis and has identified cylindrical bronchiectasis in asthma patients without allergic bronchopulmonary aspergillosis after the HRCT has been shown to be effective for allergic bronchopulmonary aspergillosis diagnostic.

The current qualitative, cross-sections analysis demonstrated that $48(38.4 \%)$ out of 125 individuals with severe persistent asthma had bronchiectasis with HRCT. This was shown by an HRCT scan in the detection of undetected bronchiectasis in serious, persistent asthma patients. Most people in this study had a history of asthma of $73.6 \%>35$ years and the average life of the disease was $28.8 \pm 7.14$ years. The mean duration of the disease was 25.7 years in Gupta et al study. ${ }^{8}$ Although bronchiectasis and asthma are in many aspects different, asthma is hard to control if the patient has both illnesses simultaneously. Most bronchiectasis asthma patients have severe asthma. ${ }^{15}$

Nevertheless, a recent study ${ }^{16}$ employed noninvasive inflammatory measurements in 40 bronchial asthma patients, generated sputum and FeNO. These authors showed that in bronchial asthma, there is eosinophil or mixed (neutrophilia \& eosinophilia) inflammation patients had higher levels of FeNO and better reversibility to bronchodilation as was the case with asthma ${ }^{17}$, compared to patients with neutrophilic inflammation or paucigranulocytic phenotype, they found that eosinophile inflammation was not mainly caused by their findings in other inflammatory parameters (IL-13, even in individuals who suffer from eosinophile inflammation, increased somewhat in bronchiectasis).

Persistent bacterial bronchiectasis of airways caused by poor ciliary transport, initiates an inflammatory cycle defined by neutrophils and neutrophil-proteases activated. Airways are also subject to persistent colonisation. ${ }^{15}$ The strength of this study is its use of the largest forwardlooking research of HRCT patients. It gives true data on bronchiectasis prevalence in asthma-uncontrolled individuals. This study concludes that in individuals with severe persistent asthma, the prevalence of bronchiectasis is still significant particularly in older individuals with a prolonged condition. For this reason, bronchiectasis should be assessed in order to effectively treat patients with severe persistent asthma to avoid an aggravation of asthma and hence to limit hospital admissions.

\section{CONCLUSION}

The prevalence of undiagnosed bronchiectasis was significantly high among patients of long disease duration suffering from persistent asthma.

\section{REFERENCE}

1. Global Initiative for Asthma (GINA). Global strategy for asthma management and prevention. 2020

2. Kim C, Kim DG. Bronchiectasis. Tuberc Respir Dis 2012;73:249-57.

3. Seitz AE, Olivier KN, Steiner CA, Montes de Oca R, Holland $\mathrm{SM}$, et al. Trends and burden of bronchiectasis-associated 
hospitalizations in the United States, 1993-2006. Chest 2010;138:944-9.

4. Oguzulgen IK, Kervan F, Ozis T, Turktas H. The impact of bronchiectasis in clinical presentation of asthma. South Med J 2007;100:468-71.

5. Hansell DM, Bankier AA, MacMahon H. Fleischner Society: glossary of terms for thoracic imaging. Radiology 2008;246:697-722.

6. Luján $M$, Gallardo $X$, Amengual MJ, Bosque M, Mirapeix $\mathrm{RM}$, Domingo C. Prevalence of bronchiectasis in asthma according to oral steroid requirement: influence of immunoglobulin levels. Biomed Res Int 2013;20:131-5.

7. Anwar GA, McDonnell MJ, Worthy SA. Phenotyping adults with non-cystic fibrosis bronchiectasis: a prospective observational cohort study. Respir Med 2013;107:1001-7.

8. Gupta S, Siddiqui S, Haldar P, Raj JV, Entwisle JJ, Wardlaw AJ, et al. Qualitative analysis of high-resolution CT scans in severe asthma. Chest 2009;136:1521-5.

9. Bisaccioni C, Aun MV, Cajuela E, Kalil J, Agondi RC, Giavina-Bianchi P. Comorbidities in severe asthma: frequency of rhinitis, nasal polyposis, gastroesophageal reflux disease, vocal cord dysfunction and bronchiectasis. Clinics (SaoPaulo) 2009;64(8):769-73.

10. Mushtaq MA, Tahir K, Tariq MW, Naqvi SSA, AtiqulMannan Muhammad, Khan A. To determine the frequency of undiagnosed Bronchiectasis in patients suffering from severe persistent Asthma in Nishter Hospital Multan. Pak J Chest Med 2018; 24 (1): 28-33.
11. Smith MP. Diagnosis and management of bronchiectasis. CMAJ 2017;189(24):E828-35.

12. Kang HR, Choi GS, Park SJ, Song YK, Kim JM, Ha J, et al The effects of bronchiectasis on asthma exacerbations. Tuberc Respir Dis. 2014;77(5):209-14.

13. Lynch DA, Newell JD, Tschomper BA, Cink TM, Newman LS, Bethel R. Uncomplicated asthma in adults: comparison of CT appearance of the lungs in asthmatic and healthy subjects. Radiology 1993;188(3):829-33.

14. Neeld DA, Goodman LR, Gurney JW, Greenberger PA, Fink $\mathrm{JN}$. Computerized tomography in the evaluation of allergic bronchopulmonary aspergillosis. Am Rev Respir Dis 1990;142(5):1200-5.

15. Angrill J, Agusti C, De Celis R, Filella X, Rano A, Elena M, et al. Bronchial inflammation and colonization in patients with clinically stable bronchiectasis. Am J RespirCrit Care Med 2001;164:1628-32.

16. Tsikrika S, Dimakou K, Papaioannou Al, Hillas G, Thanos L, Kostikas $\mathrm{K}$, et al. The role of non-invasive modalities for assessing inflammation in patients with non-cystic fibrosis bronchiectasis. Cytokine 2017;99:281-6.

17. Jatakanon A, Lim S, Kharitonov SA, Chung KF, Barnes PJ Correlation between exhaled nitric oxide, sputum eosinophils, and methacholine responsiveness in patients with mild asthma. Thorax 1998;53(2):91-5. 